\section{Familial antithrombin III deficiency}

SIR,-The impressive family study of antithrombin III (ATIII) deficiency in the west of Scotland by Dr M Mackie and his colleagues (21 January, p 136) will stimulate the search for further examples. The incidence reported by them of clinical thrombotic disease in the deficient patients (7 out of 12) and its severity follow the patterns to be found in the literature cited. It is reasonable to assume that another thrombogenic factor may be present to account for those affected clinically. It is less likely that the ATIII-deficient persons who are unaffected have special protection. The recent study ${ }^{1}$ in our laboratory of a smaller but similar family showed not only a lower rate of thromboses in the deficient ( 2 out of 9 ) but also an indication that hypertriglyceridaemia may have been the additional factor.

Deficiency of ATIII should provide a sensitive human model for the evaluation of thrombotic risk factors. Clearly these may not be the same in different families or even individuals, but it is logical to plan a comprehensive survey in any future study. Such knowledge will be of use in assessing the need for prophylaxis, which, as the authors state, is usually anticoagulation with warfarin. However, we are less certain about their suggested use of subcutaneous heparin in pregnancy. The decreased levels of ATIII found by Marciniak and Gockerman ${ }^{2}$ in patients receiving full doses of heparin for at least three days were also found in our patient who rethrombosed shortly after being taken off heparin. ${ }^{3}$ Subsequently we have measured a fall in ATIII levels of between 12 and $41 \%$ in seven patients receiving minidose subcutaneous heparin for five days after myocardial infarction. This may not be imporrant when the levels do not fall far below the normal range, but where the resting level is already $50 \%$ below normal the results may not be desirable and may account for the reported failures of heparin therapy in this condition. It is true that if, in addition to heparin, the necessary volume of plasma can be given sufficiently often to raise the level of ATIII this potential danger will not arise. The possibility of producing a plasma concentrate ${ }^{4}$ may prove to be the answer in this high-risk group.

O H B GYDE

W A LITTLER D E STABLEFoRTH

Department of Haematology,

Birmingham

1 Gyde, O H B, et al, British Medical fournal. In press.
2 Marciniak, E, and Gockerman, J P, Lancet, 1977, 2, 581.

3. Fisken, R A, et al, Lancet, 1977, 2, 1231.

SIR,-The recent report by Dr M Mackie and others (21 January, $p$ 136) of a Scottish family with familial antithrombin III (AT III) deficiency prompts us to report the first English family with the same condition. A mother and three of her four sons, living on the south coast, are affected.

The mother's AT III level measured by functional assay ${ }^{1}$ is $51 \%$ and by immunological assay ${ }^{2}$ $54 \%$. She is reported to have had deep vein thrombosis (DVT) after every pregnancy and has recently developed a spontaneous axillary vein thrombosis. Three sons have AT III levels of $48 \%$, $55 \%$, and $56 \%$ (functional) and $50 \%, 55 \%$, and $37 \%$ (immunological), respectively, while levels of $\alpha_{1}$-antitrypsin and $\alpha_{2}$-macroglobulin were found to be within normal ranges. These sons have all had recurrent DVT and have grade IV post-phlebitic legs. One son has, in addition, also had an inferior vena cava thrombosis (age 8) and mesenteric thrombosis (age 30). The father, a maternal aunt, and the fourth son and his son are asymptomatic and all have AT III levels above $80 \%$.

The typical clinical presentations are demonstrated by this small family, but the inferior vena cava thrombosis developing at the age of 8 years in one member illustrates that symptoms may not be confined only to adulthood. Mendelsohn ${ }^{3}$ has reported multiple thrombotic events in an 8-month-old infant with an AT III deficiency. Furthermore, familial AT III deficiency may not be as rare as is currently thought. Since we have started screening patients with strong family histories of venous thrombosis we have uncovered several subjects with low AT III levels and their families are now under investigation. It is our policy to recommend self-administered low dose subcutaneous heparin for all confirmed cases.

H A DE HAAS

M F SCULLY

S E CLARK

V V KAKKAR

Thrombosis Research Unit,

King's College Hospital Medical School,

' Scully, M F, and

1977, 79, and Kakkar, V V, Clinica Chimica Acta

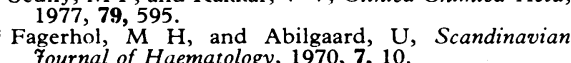
Fournal of Haematology, 1970, 7, 10 . Mendelsohn, G, Gomperts, E D, and Gurwitz, D,
Thrombosis and Haemostasis, 1976, 36, 495.

\section{Regional variations in incidence of urinary stones}

SIR, - The letters from Dr B T Williams (28 January, p 233) and $\operatorname{Dr} M J$ McCarthy (p 234) commenting on our paper (14 January, $\mathrm{p} 67$ ) again raise the question of the extent to which regional differences in provision of hospital beds nullify the use of hospital admission rates as comparative indicators of disease incidence. The degree to which admission rates reflect incidence varies from one disease to another. At one extreme patients with perforated peptic ulcers will be admitted to hospital irrespective of the number of available beds, and hospital admission rates will therefore be a measure of incidence. At the other extreme regional admission rates for non-infective skin disease show a high correlation with total numbers of dermatological beds available and the admission rates cannot be taken as indicators of incidence. Dr Williams speculates that emergency admission for renal stones and renal colic may correspond to the latter. He thereby implies that many of the patients admitted as emergencies to hospitals in southern England would, had they lived in the north of England, be looked after at home by their general practitioners.

Dr Williams's suggestion arises from the correlation (coefficient $=0.44$ ) between numbers of surgical and urological beds per 100000 population and emergency admission rates for renal stones and colic. However, numbers of beds are a poor indicator of actual availability of beds for emergency admissions because bed availability is critically influenced by patients' average duration of stay in hospital. Moreover, the low correlation coefficient of 0.44 implies that at most only $20 \%$ of the variation in admission rates is explained by variation in numbers of beds. (Likewise the correlation coefficient of 0.49 between total surgical beds and all admissions for appendicitis, which Dr Williams cites, shows that at most only $25 \%$ of the variation in appendicitis is explained in this way.)
Dr Williams suggests that the summer peak in emergency admission for renal stones and colic may merely reflect increased availability of surgical beds during the summer. He writes that "during the winter months, especially in the less wellresourced regions, surgical beds have to be "borrowed' to cater for the increased demand from patients suffering from serious acute medical conditions such as pneumonia." However, our data show that the variation in winter and summer admission rates is similar in extent in all regions, irrespective of the numbers of beds. We think his suggestion is unlikely to be true.

Dr McCarthy states that regional variations in appendicitis admissions are similar to those for renal stones. This is incorrect. The statement is based on admission rates for appendicitis quoted in the reports of the Hospital Inpatient Enquiry (HIPE). The correlation coefficient between appendicitis admissions in the most recent report, that for 1973, and the emergency admission rates for renal stones and colic cited in our paper is only 0.24 . This falls to 0.08 if the analysis is restricted to admission rates for acute appendicitis - that is, patients coded as acute appendicitis who were admitted as emergencies and operated upon (unpublished data). This points to the need for detailed analyses of HIPE data when making inferences about incidence rather than basing conclusions on the summarised data presented in published tables.

Confirmation of our conclusion that there is a higher incidence of renal stones in southern England can come only from a special survey. We agree with Mr R Scott and Dr S Ljunghall (18 February, p 439) that a survey is necessary and feasible. Two such surveys, into Paget's disease of bone ${ }^{1}$ and Perthes's disease of the hip, ${ }^{2}$ have recently been completed in this department. For both diseases HIPE data would be predicted to be inappropriate as indicators of incidence or prevalence. Yet the findings of the surveys confirmed for each disease the suggestion from HIPE analyses of a higher frequency in the north-west of England than the south.

To dismiss hospital admission rates as indicators of geographical differences in disease incidence within Britain is to take too superficial a view. Although, as we stated in our paper, biases such as those produced by regional differences in hospital admission practice cannot be eliminated, we nevertheless think that detailed analyses of HIPE data are a useful preliminary in geographical studies of disease incidence.

D J P BARKER $S$ P B DONNAN

University Department of Southampton General Hospital, Southampton

${ }^{1}$ Barker, D J P, et al, British Medical fournal, 1977, 1, 1181 .

Barker, D J P, Paper read to meeting of Society for Social Medicine, Birmingham, September 1977.
.

\section{Duration of immunity conferred by} rubella vaccines

SIR,-The short reply in your Any Questions column (3 December, p 1466) on the duration of immunity provided by rubella vaccines implies that it is only a matter of time before studies confirm that vaccination confers lifelong protection. Your expert also wrongly implies that all vaccine strains are equivalent or that the strains of vaccine principally used in vaccination programmes in the United States and Great Britain are the same. Many studies have shown that the immediate antibody responses elicited by vaccination differ with strains $s^{1-4}$ and others ${ }^{5-13}$ indicate 
that some strain differences in long-term persistence of antibody may be expected. It is possible that some of the vaccinees who apparently lose circulating antibody after vaccination may be protected against infection by low levels not detected by the test procedures used. On the other hand second attacks of rubella are documented, ${ }^{14}{ }^{15}$ as is fetal damage from reinfection. ${ }^{16}$ In the United States and Great Britain peak child-bearing is at the age of 24 years, and since the duration of protection induced by vaccination is not yet assured the policy of vaccinating girls between their eleventh and fourteenth birthdays still seems to have merit in comparison with the American system of vaccinating children before school entry.

D S FREESTONE

S K HASELL

Department of Clinical

Immunology and Chemotherapy,

Wellcome Research

1 Plotkin, S A, Farquhar, J D, and Ogra, P L, fournal of the American Medical Association, 1973, 225, 585 - Freestone, D S, British fournal of Preventive and Social Medicine, 1974, 28, 258.

Le Bouvier, G L, and Plotkin, S A, fournal of Infectious Diseases, $1971,123,220$.

allace, R B, and Isacson, P, American fournal of Diseases of Children, 1972, 124, 536.

Hillary, I B, and Freestone, D S, fournal of Hygiene,

Buser, F, Praxis, 1975, 64, 88

MacDonald, H, and Tobin, J O'H, quoted by Banatvala, J E, in Recent Advances in Clinical Virologyp 171. Edinburgh, Churchill Livingstone, 1977. Children, 1974, 128 , American

Rauh, J L, et al, fournal of Pediatrics, 1975, 86, 138 10 Rauh, J L, et al, fournal of Pediatrics, 1975, 86, 138 Association, 1976, 235, 2201.

1 Balfour, H H, and Amren, D P, Lancet, 1977, 2, 1130 12 Horstmann, D M, Annals of Internal Medicine, 1975 83, 412 .

13 Weibel, R E, et al, Pediatrics, 1975, 56, 380.

14 Watson, G I, Lancet, 1965, 1, 80

15 Wilkins, J, et al, Annals of Internal Medicine, 1972, 77, 16930.

Eilard, T, and Strannegard
Diseases, 1974, 129, 594.

***Our expert writes: "I am grateful to Drs Freestone and Hasell for their thoughtful comments about the duration of immunity provided by rubella vaccines and for their painstaking review of the literature. As they point out, the relationship between demonstrable circulating antibody and clinical protection must always be uncertain. The only truly valid measure of duration of immunity will be the incidence of congenital rubella among vaccinees compared with that among the unvaccinated. The cited instances of natural infections amount to three cases, in one of which the evidence is uncertain. These rare events, which may be related to host factors rather than time intervals between exposures to infection, do not in my opinion constitute an argument against a long duration of vaccine-induced immunity."

\section{Papilloedema in patients taking perhexiline maleate}

SIR,-In reply to the letter from $\mathrm{Dr} W \mathrm{~W}$ Hutchinson and others (4 February, p 305) we would like to make two points. Each of the patients reported in our paper ( 7 January, p 21) presented with severe headaches; these were often worse early in the morning and sometimes associated with nausea. We feel that the combination of these headaches and the gross papilloedema observed is good presumptive evidence of raised intracranial pressure. We accept that the only way to prove a true increase in intracranial pressure is to make a direct measurement, but we felt that the risks to the patients outweighed the benefits of what was largely an academic exercise. It is not clear if the man reported by Dr Hutchinson and his colleagues was experiencing headaches.

Secondly, they quote Bousser's paper ${ }^{1}$ and say that "a high CSF protein concentration was noted, up to $10 \mathrm{~g} / \mathrm{l}$." However, the three patients reported with neuropathy and papilloedema had CSF protein concentrations of $1 \cdot 75,4 \cdot 2$, and $1.35 \mathrm{~g} / 1$ respectively. One patient with neuropathy alone had a CSF protein of $3.2 \mathrm{~g} / \mathrm{l}$. These are, of course, much lower than the levels suggested by Dr Hutchinson's letter.

It is open to debate whether a comparison to the Guillain-Barré syndrome is valid, and certainly on the present evidence abnormalities in CSF protein are unlikely to give the complete answer to the aetiology of papilloedema due to perhexiline maleate.

W P STEPHENS J D EDDY

Good Hope General Hospital, W Midlands

S P SINGH

Dudley Road Hospital,

Birmingham

Bousser, M G, et al, Coeur et Médecine Interne, 1976, 15,181 .

\section{Postoperative chest infections}

SIR,-Your leading article (10 December, p 1500) and Drs J L Craven and G A Evans (28 January, p 237) emphasise the importance of deep breathing in the prevention of postoperative respiratory complications. Nobody has mentioned the therapeutic value of respiratory stimulants given soon after operation. Four independent studies ${ }^{1-4}$ have shown a significant reduction of coughing and excessive production of purulent sputum or other respiratory complications in patients given either a single dose (1-1.5 mg/kg body weight) or infusion of doxapram wit a the first postoperative analgesic.

Department of Anaesthetics,

JO-IN W DUNDEE Queen's University,

${ }^{1} \mathrm{Gu}$

Gupta, P K, and Dundee, J W, Anaesthesia, 1974, 29, Lees, N W, et al, British fournal of Anaesthesia, 1976, Gawley, T H, et al, British Medical fournal, 1976, Downing, J W, Jeal, D E, Allen, P J, and Buley,
British fournal of Anaesthesia, 1977, 49, 473.

\section{Lymphocytotoxic antibodies in}

\section{spontaneous cytomegalovirus infection}

SIR,-Cold-reactive lymphocytotoxic antibodies (LCA) have been demonstrated in patients with acute viral infections such as infectious mononucleosis, measles, and rubella ${ }^{1}$ and in normal individuals following immunisation with viral vaccines. ${ }^{2}$ They have also been detected in patients suffering from other diseases thought to be related to viral infection, such as systemic lupus erythematosus, rheumatoid arthritis, ${ }^{3}$ multiple sclerosis, ${ }^{4}$ etc.

We have found LCA in the serum of all of five patients with primary cytomegalovirus (CMV) infection (CMV mononucleosis) CMV infection was demonstrated by the isolation of the virus from saliva or urine, by the demonstration of a fourfold rising CMV complement-fixing antibody titre, or by both methods. In addition, in all patients an elevated $\mathrm{CMV}$ specific IgM antibody titre was demonstrated. These five patients had not received blood transfusions within the six months before infection and were considered to be suffering from spontaneous CMV infection. In contrast, we have not found LCA in the serum of four patients with CMV mononucleosis occurring within four weeks after multiple blood transfusions.

Spontaneous, but not transfusion-associated, CMV infection should be added to the list of diseases causing the appearance of LCA. The finding of LCA in spontaneous CMV infection, besides its theoretical interest, may have some practical implications. If, for instance, LCA are found during screening for HLA antibodies in the serum of patients on dialysis waiting for a kidney transplant one should look for a CMV or other virus infection. In addition it is important to distinguish LCA from anti-HLA antibodies because their significance may be different. $\mathrm{We}^{5}$ and others ${ }^{6}$ have shown that cold-reactive LCA, in contrast to warm-reactive anti-HLA antibodies, are associated with a good survival of kidney transplants.

Michel JeANNET HANS STALDER

Transplantation Immunology Unit

and Division of Infectious Diseases,

Department of Medicine,

Hopital Cantonal,

Mottironi, V D, and Terasaki, P I, in Histocompatibility Testing, ed P T Terasaki, p 301 . Copenhagen, Munksgaard, 1970

${ }^{2}$ Kreisler, M J, Hirata, A A, and Terasaki, P I Transplantation, 1970, 10, 411

${ }^{3}$ Terasaki, P I, Mottironi, V D, and Barnett, E V New England fournal of Medicine, 1970, 283,724. Schocket, $A$ L, et al, Clinical Immunology and Immunopathology, 1977, 7, 15.

S Klouda, P T, and Jeannet, M, Lancet, 1976, 1, 876. tastny, $P$, and Austin, C L, Transplantation, 1976

\section{Breast lumps in adolescent girls}

SIR,-I read with interest your leading article on the above subject (4 February, p 260) but must disagree with the conclusions reached.

Over the years I have seen a very large number of such lumps and have always adopted an expectant approach, which you condemn. None of my cases has ever "gone wrong" and in many cases the lump has disappeared and the girl has been saved an unnecessary operation. Whether the fibroadenoma actually disappears or is merely masked by the growth of healthy breast tissue I don't know, but at all events the lump is no longer palpable and that is all that matters. Some 20 years ago, when I started to aspirate breast cysts, I attempted this with several young girls but soon realised that cystic as opposed to solid lumps at this age are a rarity and that attempts to aspirate are not worth while. You quote the case of a girl of 15 with a fatal carcinoma, but does a rarity so great that probably only one in 10 surgeons will see such a case in a surgical lifetime really justify a change of policy ? Would earlier diagnosis in this case really have mattered anyway? She may well have been saved at least some of the mutilating surgery, chemotherapy, and radiotherapy that she would certainly have had, and which equally certainly would have made no difference to the ultimate result.

Needless to say I am in complete agreement with your remarks about the as'mmetrical 